\title{
Premature mortality due to alcohol-related diseases of the liver in Poland according to voivodships
}

\author{
PAULINA PACIEJ ${ }^{\mathrm{C}-\mathrm{F}}$, BEATA CIABIADA ${ }^{\mathrm{B}, \mathrm{C}}$, IRENA MANIECKA-BRYŁA ${ }^{\mathrm{A}, \mathrm{B}, \mathrm{G}}$ \\ Department of Epidemiology and Biostatistics, Medical University of Lodz, Poland
}

A - Study Design, B - Data Collection, C - Statistical Analysis, D - Data Interpretation, E - Manuscript Preparation, F - Literature Search, G - Funds Collection

Summary Background. Alcohol is one of the most serious public health threats facing the global population. Of all disease risk factors, alcohol ranks ninth place globally and sixth in Poland, with regards to DALYs (Disability-Adjusted Life Years). DALYs consist of two components: YLL (Years of Life Lost) and YLD (Years of Life with Disability).

Objectives. The aim of the study was to assess the number of years of life lost due to alcohol-related diseases of the liver in the Polish population in 2013 according to voivodships.

Material and methods. The study was based on 387,312 records obtained from the death certificates of Poles who died in 2013. The data on deaths caused by alcohol-related diseases of the liver (alcoholic liver disease, fibrosis and cirrhosis of the liver) were used for the analysis. The SEYLL (Standard Expected Years of Life Lost) was used to calculate the years of life lost.

Results. In 2013, alcohol-related diseases of the liver caused 6,126 deaths of Poles, resulting in a loss of 129,578.8 years of life in the group of men $(69.5$ per 10,000$)$ and $51,280.3$ years in the group of women $(25.8$ per 10,000$)$. The highest number of years of life lost was noted in the voivodships of Śląskie (102.5 per 10,000 males and 45.9 per 10,000 females) and Łódzkie ( 97.3 and 33.6, respectively), and the lowest in Podkarpackie (49.3 and 10.4, respectively).

Conclusions. Premature deaths caused by alcohol-related diseases of the liver are a considerable problem in the Polish population. The particular challenge in public health activities is to reduce the inconsistencies in health between voivodships.

Key words: premature mortality, years of life lost, alcohol, diseases of the liver.

Paciej P, Ciabiada B, Maniecka-Bryła I. Premature mortality due to alcohol-related diseases of the liver in Poland according to voivodships. Fam Med Prim Care Rev 2017; 19(3): 251-255, doi: https://doi.org/10.5114/fmpcr.2017.69287.

\section{Background}

Alcohol is one of the most serious public health threats facing the global population. According to the WHO (World Health Organization), about 3.3 million people die from its effects each year; this constitutes $5.9 \%$ of all deaths. For many years, the highest alcohol intake has been recorded in Europe, accounting for $25.7 \%$ of globally consumed alcohol. While worldwide only 6.2 liters of alcohol is drunk per person yearly, the average for Europe is about 10.9 liters per person yearly $[1,2]$.

In Poland, an increasing trend in alcohol consumption has been noted for years; since 2006, alcohol intake has not dropped below 10 liters per person. Furthermore, since 2008, Poland's individual alcohol consumption has exceeded the average for the EU (European Union). In 2014, this was 10.7 liters of alcohol per Polish resident, while the EU average was 10.2 liters per person [3].

Alcohol-related hazards depend not only on the amount of alcohol intake, but also on the type of alcoholic beverage drunk [4]. On average in Poland, more than $50 \%$ of consumed alcohol is beer, about $40 \%$ is spirits, and less than $10 \%$ is wine. These proportions are only becoming more concerning with an increasing amount of beer and spirits and a decreasing amount of wine being consumed in Poland. In 2014, 6.45 liters of beer (60.2\%), 3.4 liters of spirits (31.8\%) and 0.86 liters of wine (8\%) per capita were consumed; while in 2000, it was 4.14 liters of beer $(49.3 \%), 2.48$ liters of spirits (29.5\%) and 1.78 liters of wine (21.2\%) per capita [3].

Currently, more than 200 diseases and health problems are linked with excessive alcohol consumption. Among them, neuropsychiatric disorders, injuries, liver cirrhosis, acute and chronic pancreatitis, malignant neoplasms and cardiovascular diseases play a dominant role [5].

Of all disease risk factors, alcohol ranks ninth globally and sixth in Poland, with regards to DALYs (Disability-Adjusted Life Years) [6]. According to the WHO, in 2012, about 5.1\% of all DALYs were due to diseases caused by alcohol [1].

DALYs consist of two components: YLL (Years of Life Lost) and YLD (Years of Life with Disability). As a measure of disease burden, it provides a more complex assessment of the health status of a population than the conventionally used ratios, while its YLL component particularly serves to evaluate premature mortality $[7,8]$.

In 2011, liver cirrhosis was the third most important cause of YLLs per one death in Poland, followed by traffic accidents and suicides. The number of premature years of life lost due to liver cirrhosis was then 12.1 per one male death and 11.3 per one female death. These were substantially higher than the average numbers of years of life lost among all diseases -7.1 and 4.7 , respectively [9].

Based on these differences, liver cirrhosis, which in $80 \%$ of cases may be associated with excessive alcohol consumption, might play a major role in a loss of lifetime potential in the Polish population [10]. This raises the need for more detailed analysis of premature mortality due to alcohol-related diseases among Poles. Evaluating, by voivodships, the years of life lost associated with these diseases will hopefully help to reduce the inequalities between local communities [11].

\section{Objectives}

The aim of this study was to assess the number of years of life lost caused by alcohol-related diseases of the liver in the Polish population in 2013 according to voivodships. 


\section{Material and methods}

The study was based on a dataset provided by the Central Statistical Office in Poland, created on the basis of the death certificates of Poles who died in 2013, comprising 387,312 records. Data on deaths caused by alcohol-related diseases of the liver were analyzed, i.e. $\mathrm{K} 70$ - alcoholic liver disease, K74 - fibrosis and cirrhosis of the liver, according to the ICD-10 (International Classification of Diseases and Related Health Problems $-10^{\text {th }}$ Revision). Due to the lack of availability to follow the medical records of patients, it was not possible to extract the cases of fibrosis and cirrhosis of the liver caused only by alcohol.

As a measure of years of life lost, we used SEYLL (Standard Expected Years of Life Lost), calculated according to the method implemented by Murray and Lopez [8]:

$$
S E Y L L=\sum_{\chi=0}^{I} d_{\chi} e_{\chi}^{*}
$$

where:

$e_{\chi}^{*}$-is the average life expectancy for a particular age determined on the basis of standard population,

$d_{\chi}-$ is the number of deaths at age $\chi$,

$\chi$-is the age of death,

$I-$ is the oldest age in the population.

The expected lifespan for each age was established using the life table published by the WHO in 2012 [12]. According to this source, the life expectancy for both genders at age 0 is 86.02 years. The values given in the table were not adjusted for age or discounted over time.

We also implemented SEYLL ${ }_{p}$ (Standard Expected Years of Life Lost per person), which is a ratio of the number of years of life lost and the size of a population, calculated per 10,000 inhabitants. SEYLL ${ }_{d}$ (Standard Expected Years of Life Lost per death), which describes the number of years of life lost per one death, was calculated by dividing the number of years of life lost by the number of deaths caused by a particular disease.

\section{Results}

In 2013, alcohol-related diseases of the liver caused 6,126 deaths, which accounted for $1.58 \%$ of all deaths of Poles in the analyzed year. The studied diseases (K70 and K74) were the cause of $89.32 \%$ of deaths from all diseases of the liver (K70-K77). Alcoholic liver disease (K70) caused 3,423 deaths ( $55.88 \%$ of deaths): 2,636 deaths of men and 787 deaths of women; and fibrosis and cirrhosis of the liver (K74) caused 2,703 deaths ( $44.12 \%$ of deaths): 1,613 deaths of men and 1,090 deaths of women. The highest number of deaths was recorded in the Śląskie voivodship $(1,146)$, and the lowest was in the Świętokrzyskie voivodship (148) (Table 1).

In 2013, alcohol-related diseases of the liver were the cause of 180,859 years of life lost: $129,578.81$ years in the group of men and 51,280.28 in the group of women. This constituted $89.97 \%$ of the SEYLL associated with all diseases of the liver in the analyzed year. These figures translate to 46.97 premature years of life lost per 10,000 inhabitants (SEYLL $)$ : 69.54 years per 10,000 males and 25.81 years per 10,000 females. A person who died due to an alcohol-related disease of the liver over the analyzed time lost on average (SEYLL $) 29.52$ years of life. In the group of men, SEYLL ${ }_{d}$ was 30.50 years, and in the group of women, it was 25.81 years.

The highest SEYLL due to the studied diseases was noted in the voivodships of Śląskie (102.48 per 10,000 males and 45.93 per 10,000 females) and Łódzkie (97.27 per 10,000 males and 33.61 per 10,000 females). It was the lowest in the Podkarpackie voivodship (49.33 per 10,000 males and 10.43 per 10,000 females).

The highest number of years of life lost calculated per one male death was noted in the Warmińsko-Mazurskie voivodship (33.74 years), and the lowest was in the Zachodniopomorskie voivodship (28.55 years). In the group of women, the highest number of years of life lost per death was also noted in the Warmińsko-Mazurskie voivodship (35.02 years), while the lowest was recorded in the Opolskie voivodship (22.45 years) (Table 2).

\begin{tabular}{|c|c|c|c|c|c|c|c|}
\hline \multirow[t]{2}{*}{ Voivodship } & \multicolumn{3}{|l|}{ Men } & \multicolumn{3}{|c|}{ Women } & \multirow[t]{2}{*}{$M / W$} \\
\hline & K70 & K74 & Total & K70 & K74 & Total & \\
\hline Dolnośląskie & 167 & 176 & 343 & 52 & 105 & 157 & 2.18 \\
\hline Kujawsko-Pomorskie & 90 & 117 & 207 & 26 & 64 & 90 & 2.30 \\
\hline Lubelskie & 112 & 87 & 199 & 37 & 38 & 75 & 2.65 \\
\hline Lubuskie & 93 & 39 & 132 & 33 & 28 & 61 & 2.16 \\
\hline Łódzkie & 240 & 114 & 354 & 78 & 82 & 160 & 2.21 \\
\hline Małopolskie & 156 & 135 & 291 & 32 & 81 & 113 & 2.58 \\
\hline Mazowieckie & 441 & 110 & 551 & 111 & 113 & 224 & 2.46 \\
\hline Opolskie & 67 & 43 & 110 & 26 & 26 & 52 & 2.12 \\
\hline Podkarpackie & 78 & 97 & 175 & 8 & 39 & 47 & 3.72 \\
\hline Podlaskie & 108 & 33 & 141 & 25 & 24 & 49 & 2.88 \\
\hline Pomorskie & 173 & 67 & 240 & 63 & 57 & 120 & 2.00 \\
\hline Śląskie & 407 & 341 & 748 & 137 & 261 & 398 & 1.88 \\
\hline Świętokrzyskie & 66 & 41 & 106 & 21 & 21 & 42 & 2.52 \\
\hline Warmińsko-Mazurskie & 154 & 1 & 155 & 49 & 2 & 51 & 3.04 \\
\hline Wielkopolskie & 174 & 135 & 309 & 51 & 102 & 153 & 2.02 \\
\hline Zachodniopomorskie & 111 & 77 & 188 & 38 & 47 & 85 & 2.21 \\
\hline Total & 2,636 & 1,613 & 4,249 & 787 & 1,090 & 1,877 & 2.26 \\
\hline
\end{tabular}

K70 - alcoholic liver disease; K74 - fibrosis and cirrhosis of the liver; M/W - ratio of the number of deaths of men and women. 


\begin{tabular}{|c|c|c|c|c|c|c|}
\hline \multirow[t]{2}{*}{ Voivodship } & \multicolumn{3}{|l|}{ Men } & \multicolumn{3}{|l|}{ Women } \\
\hline & SEYLL & SEYLL & SEYLL $_{d}$ & SEYLL & SEYLL, & SEYLL $d$ \\
\hline Dolnośląskie & $10,324.57$ & 73.74 & 30.10 & $4,318.46$ & 28.58 & 27.51 \\
\hline Kujawsko-Pomorskie & $6,047.59$ & 59.58 & 29.22 & $2,348.55$ & 21.76 & 26.10 \\
\hline Lubelskie & $6,009.73$ & 57.39 & 30.20 & $2,196.24$ & 19.73 & 29.28 \\
\hline Lubuskie & $4,803.66$ & 82.02 & 30.94 & $1,509.93$ & 28.80 & 24.75 \\
\hline Łódzkie & $11,672.56$ & 97.27 & 32.97 & $4,428.62$ & 33.61 & 27.68 \\
\hline Małopolskie & $8,987.82$ & 55.19 & 30.89 & $2,818.32$ & 16.31 & 24.94 \\
\hline Mazowieckie & $16,795.94$ & 66.14 & 30.48 & $6,234.33$ & 22.52 & 27.83 \\
\hline Opolskie & $3,239.13$ & 66.52 & 29.45 & $1,427.35$ & 27.45 & 22.45 \\
\hline Podkarpackie & $5,141.72$ & 49.33 & 29.38 & $1,132.68$ & 10.43 & 24.10 \\
\hline Podlaskie & $4,258.40$ & 72.96 & 30.20 & 1,390.75 & 22.69 & 28.38 \\
\hline Pomorskie & $7,165.27$ & 64.10 & 29.86 & $3,123.99$ & 26.59 & 26.03 \\
\hline Śląskie & $22,787.51$ & 102.48 & 30.46 & $10,945.22$ & 45.93 & 27.50 \\
\hline Świętokrzyskie & $3,311.09$ & 53.37 & 31.24 & $1,167.16$ & 17.96 & 27.79 \\
\hline Warmińsko-Mazurskie & $5,230.09$ & 73.73 & 33.74 & $1,786.19$ & 24.17 & 35.02 \\
\hline Wielkopolskie & $9,156.12$ & 54.35 & 29.63 & $4,055.91$ & 22.80 & 26.51 \\
\hline Zachodniopomorskie & $5,367.61$ & 64.09 & 28.55 & $2,396.58$ & 27.17 & 28.20 \\
\hline Total & $129,578.81$ & 69.54 & 30.50 & $51,280.28$ & 25.81 & 27.32 \\
\hline
\end{tabular}

\section{Discussion}

Diseases of the digestive system are the fifth leading cause of mortality in the Polish population, followed by cardiovascular diseases, malignant neoplasms, external causes and diseases of the respiratory system [13-17]. Among the diseases of the digestive system (KO0-K93), diseases of the liver make up the highest share in deaths. Particularly alcohol-related diseases, i.e. alcoholic liver disease and fibrosis and cirrhosis of the liver, contribute the most $[18,19]$.

According to data of Eurostat, in Poland in 2013, the standardized mortality rate due to chronic diseases of the liver (K70, K73, K74) was 16.91 per 100,000 inhabitants: 25.47 per 100,000 males and 9.61 per 100,000 females. This placed Poland thirteenth among all the EU-28 countries. For years, the values of this rate for the Polish population have been exceeding the average for the European Union, which was 14.71 per 100,000 inhabitants in 2013 and only 21.44 for men and 8.81 for women. Among the EU-28 countries, the highest standardized mortality rates were observed in Romania (46.73 per 100,000; 65.83 for men and 31.08 for women), in Hungary ( 31.57 per 10,000; 53.11 for men and 15.13 for women) and in Lithuania (30.92 per 100,000; 45.03 for men and 19.99 for women). The lowest mortality rates were observed in the Netherlands ( 4.73 per 100,$000 ; 6.03$ for men and 3.55 for women), in Norway (4.79 per 100,$000 ; 6.10$ for men and 3.59 for women) and in Malta (5.51 per 100,000; 9.11 for men and 2.31 for women) [19].

In terms of the number of premature years of life lost, diseases of the digestive system also rank fifth in the Polish population [9]. Among these diseases each year, most YLLs are caused by alcoholic liver disease, fibrosis and cirrhosis of the liver and acute pancreatitis [18]. The dominant role in the pathogenesis of these diseases is played by alcohol. It is estimated that 60 $-80 \%$ of liver cirrhosis cases are caused by excessive consumption of alcohol [10]. Less often, they are caused by other factors, such as hepatotropic viruses, autoimmune diseases, bile stuck in the course of various illnesses, drugs and other toxins [20]. As another example, acute pancreatitis is associated with alcohol consumption in $30-50 \%$ of cases [21, 22].

Epidemiological comparisons between countries in terms of the number of years of life lost by a specific cause are difficult.
There is a lack of accurate data on premature mortality caused by particular diseases, and various methods are used to calculate YLLs. In the presented study, we applied SEYLL to analyze the number of years of life lost. However, other potential measures are also in use, such as PYLL (Potential Years of Life Lost) or PEYLL (Period Expected Years of Life Lost). PYLL uses a value between 60 and 85 years as a limit of life expectancy, and PEYLL evaluates the expected lifespan based on local life tables $[23,24]$. On the other hand, SEYLL adapts the lifetime table of a population considered as referential. In our study, we applied a table published by the WHO in 2012, created on the basis of the data from countries with the lowest mortality rates and at least 5,000,000 inhabitants [12]. In older studies, tables using the population of Japan as a standard (Coale-Demeny's table) or the average for the 15 "old" EU countries, or sometimes 27 , were in use $[9,18]$.

According to the GBD (Global Burden of Disease) [25], in Poland in 2013, chronic diseases of the liver were the cause of 61.10 years of life lost per 10,000 inhabitants. The significant discrepancy between this result and the one obtained in our study ( 46.97 years per 10,000 inhabitants) is due to the fact that the GBD presented the values for a larger group of diseases, which also included diseases of the liver with an infectious etiology. From the GBD data, Poland ranks eighth in the EU-28 in terms of years of life lost due to chronic liver diseases, followed by Romania (136.05 years per 10,000 inhabitants), Hungary (107.21 years) and Lithuania (101.71 years).

In the presented study, the analysis of years of life lost due to alcohol-related diseases of the liver in the Polish population according to voivodships was established for the first time. The presence of significant inequalities seen between the voivodships is of a concern - the numbers of years of life lost for men in the Śląskie (SEYLLp = 102.48) and Łódzkie voivodships (SEYLLp $=97.27$ ) were two times higher than in Podkarpackie voivodship (SEYLLp $=49.33$ ). The differences between these voivodships were even larger in the group of women $\left(\mathrm{SEYLL}_{p}=45.93\right.$ and 33.61 vs 10.43 , respectively). In each voivodship, a significant difference in the number of years of life lost between the group of men and women emerged; this ratio was on average 2.69 . However, in the Podkarpackie voivodship, the SEYLL value in the group of men was almost five times higher than in the group of women. The values of SEYLL ${ }_{d}$ were not much different be- 
tween the voivodships or between the genders. This suggests that these variables are not related to the lifespan of patients suffering from fibrosis and cirrhosis of the liver or alcoholic liver disease.

Certainly, the use of the methods in accordance with the current recommendations of the WHO and GBD was a great advantage to the presented study. The authors, however, are also aware of some limitations. The research was based on death certificates of Polish citizens; therefore, possible inaccuracies caused by incorrect coding of the causes of deaths could have led to the collection and use of false information. This is possibly exemplified, for instance, in the data from the WarmińskoMazurskie voivodship, which significantly stood out from the results of other voivodships, i.e. fibrosis and cirrhosis of the liver were diagnosed only in one man and two women (Table 1). Moreover, some cases of alcoholic liver disease or fibrosis and cirrhosis of the liver might not have been included in the study if the patients were subject to multiple morbidity causes and another health problem was recorded as the primary cause of death. However, these limitations are unavoidable for most of the studies that use data on deaths without the possibility to follow the medical records of the deceased.

What is more, in our study, we considered records classified only as K70 or K74 as alcohol-related diseases of the liver. However, some authors extended their analyses to other diseases. In certain studies, malignant neoplasms of the liver (C22) [26], infectious diseases (B18) or complications due to liver cir- rhosis (esophageal varices - 185) were included. Others also incorporated other diseases of the liver, some with four-character codes (toxic liver disease with fibrosis and cirrhosis of the liver - K71.7, hepatic failure not elsewhere classified - K72.1-K72.9, chronic hepatitis not elsewhere classified $-\mathrm{K} 73$, other inflammatory liver diseases - K75.2-K75.9, portal hypertension and hepatorenal syndrome - K76.6-K76.7, unspecified liver disease - K76.9) [27]. Methodological differences complicate the comparison of results obtained by different researchers.

\section{Conclusions}

An analysis of the epidemiological situation using the SEYLL measure provides significant information on the health and socio-economic aspects of premature mortality. The results of this study indicate that premature deaths caused by alcohol-related diseases of the liver are a significant problem in the Polish population. Moreover, it demonstrates that Polish voivodships are experiencing these diseases and their consequences unequally. The particular challenge faced by public health activities is to reduce the inconsistencies of health between these local communities. There is a need to combat unfavorable drinking habits throughout society. Further research on the drinking habits among residents of different voivodships is essential in order to implement effective methods to limit the years of life lost associated with these diseases.

Source of funding: This work was funded by the Medical University of Lodz on the basis of decision number 503/6-029-07/503-61-001. Conflict of interest: The authors declare no conflict of interests.

\section{References}

1. World Health Organization. Global status report on alcohol and health 2014 [cited 20.02.2017]. Available from URL: http://www.who. int/substance_abuse/publications/global_alcohol_report/msb_gsr_2014_1.pdf.

2. Anderson P, Baumberg B. Alcohol in Europe. London: Institute of Alcohol Studies; 2006.

3. World Health Organization Regional Office for Europe. European health for all database [cited 20.02.2017]. Available from URL: http:// data.euro.who.int/hfadb/.

4. Rehm J, Sulkowska U, Mańczuk M, et al. Alcohol accounts for a high proportion of premature mortality in central and eastern Europe. Int J Epidemiol 2007; 36(2): 458-467.

5. Parry C, Patra J, Rehm J. Alcohol consumption and non-communicable diseases: epidemiology and policy implications. Addiction 2011; 106(10): 1718-1724.

6. Vos T, Allen C, Arora M, et al. Global, regional, and national incidence, prevalence, and years lived with disability for 310 diseases and injuries, 1990-2015: a systemic analysis for the Global Burden of Disease Study. Lancet 2016; 388(10053): 1545-1602.

7. Murray CJL. Quantifying the burden of disease: the technical basis for disability-adjusted life years. Bull World Health Organ 1994; 72(3): 429-445.

8. Murray CJL, Lopez AD. The Global Burden of Disease. A comprehensive assessment of mortality and disability from diseases, injuries and risk factors in 1990 and projected to 2010. Boston: Harvard University Press; 1996.

9. Maniecka-Bryła I, Bryła M, Bryła P, et al. The burden of premature mortality in Poland analysed with the use of standard expected years of life lost. BMC Public Health 2015; 15: 101, doi: 10.1186/s12889-015-1487-x.

10. Sheron N. Alcohol and liver disease in Europe - simple measures have the potential to prevent tens of thousands of premature deaths. $J$ Hepatol 2016; 64(4): 957-967.

11. World Health Organization Collaborating Centre for Policy Research on Social Determinants of Health. European strategies for tackling social inequalities in health: levelling up Part 2 [cited 20.02.2017]. Available from URL: http://www.euro.who.int/_data/assets/ pdf_file/ 0018/103824/E89384.pdf.

12. Murray CJL, Ezzati M, Flaxman AD, et al. GBD 2010: design, definitions, and metrics. Lancet 2012; 380(9859): $2063-2066$ (Supplement).

13. Dmochowska H. Rocznik statystyczny Rzeczypospolitej Polskiej 2015. Warszawa: Główny Urząd Statystyczny; 2015 (in Polish).

14. Maniecka-Bryła I, Pikala M, Bryła M. Life years lost due to cardiovascular diseases. Kardiol Pol 2013; 71(10): 1065-1072.

15. Pikala M, Maniecka-Bryła I. Years of life lost due to malignant neoplasms characterized by the highest mortality rate. Arch Med Sci 2014; 10(5): 999-1006.

16. Pikala M, Bryła M, Bryła P, et al. Years of life lost due to external causes of death in the Lodz province, Poland. PLoS One 2014; 9(5): 1-10, doi: https://doi.org/10.1371/journal.pone.0096830.

17. Maniecka-Bryła I, Paciej P, Dziankowska-Zaborszczyk E, et al. Lost life years due to premature mortality caused by diseases of the respiratory system. Adv Clin Exp Med 2017; (in press).

18. Paciej P, Ciabiada B, Maniecka-Bryła I. Lost life years due to premature deaths caused by diseases of the digestive system in Poland in 2013. Przegl Epidemiol 2016; 70(3): 500-507.

19. Eurostat. General mortality [cited 20.02.2017]. Available from URL: http://ec.europa.eu/eurostat/web/health/causes-death/data/database.

20. Stickel F, Datz C, Hampe J, et al. Pathophysiology and management of alcoholic liver disease: Update 2016. Gut Liver 2017; 11(2): $173-188$ 
21. Lankisch PG, Assmus C, Pflichthofer D, et al. Which etiology causes the most severe acute pancreatitis? Int J Pancreatol 1999; 26(2): 55-57.

22. Hentic O, Lévy P, Hammel P, et al. Are the causes similar for benign and severe forms of acute pancreatitis? Gastroenterol Clin Biol 2003; 27(4): 403-406.

23. Romeder JM, McWhinnie JR. Potential years of life lost between ages 1 and 70: an indicator of premature mortality for health planning. Int J Epidemiol 1977; 6(2): 143-151.

24. Penner D, Pinheiro $P$, Krämer A. Measuring the burden of disease due to premature mortality using standard expected years of life lost (SEYLL) in North Rhine-Westphalia, a federal state of Germany, in 2005. JPH 2010; 18: 319-325.

25. Global Health Data Exchange [cited 20.02.2017]. Available from URL: http://ghdx.healthdata.org/gbd-results-tool.

26. Rehm J, Samokhvalov AV, Shield KD. Global burden of alcoholic liver diseases. J Hepat 2013; 59(1): 160-168.

27. Mokdad AA, Lopez AD, Shahraz S, et al. Liver cirrhosis mortality in 187 countries between 1980 and 2010: a systematic analysis. BMC Medicine 2014; 12: 145, doi: 10.1186/s12916-014-0145-y.

Tables: 2

Figures: 0

References: 27

Received: 12.04 .2017

Revised: 26.06 .2017

Accepted: 01.07.2017

Address for correspondence:

Paulina Paciej, MD

Zakład Epidemiologii i Biostatystyki UM

ul. Żeligowskiego $7 / 9$

90-742 Łódź

Polska

Tel.: +48 609 915-997

E-mail: paulina.paciej@stud.umed.lodz.pl 